\title{
GNSS Multipath Reduction Using GPS and DGPS in the Real Case
}

\author{
Salem Titouni ${ }^{1}$, Khaled Rouabah ${ }^{1}$, Salim Atia ${ }^{1}$, Mustapha Flissi $^{1}$, Oussama Khababa ${ }^{2}$ \\ ${ }^{1}$ Electronics Department, ETA Laboratory, University of Mohamed El-Bachir El-Ibrahimi, Bordj Bou Arreridj, Algeria \\ ${ }^{2}$ Engineering Office \& Technical Studies, Bordj Bou Arreridj, Algeria \\ Email: titouni.salem@gmail.com
}

How to cite this paper: Titouni, S., Rouabah, K., Atia, S., Flissi, M. and Khababa, O. (2017) GNSS Multipath Reduction Using GPS and DGPS in the Real Case. Positioning, 8, 47-56.

https://doi.org/10.4236/pos.2017.84004

Received: August 17, 2017

Accepted: October 10, 2017

Published: October 13, 2017

Copyright (c) 2017 by authors and Scientific Research Publishing Inc. This work is licensed under the Creative Commons Attribution International License (CC BY 4.0).

http://creativecommons.org/licenses/by/4.0/

\section{cc) (i) Open Access}

\begin{abstract}
In Global Navigation Satellite System (GNSS) like Global Positioning System (GPS) and future Galileo, space signal reception in urban environment seems to be one of most significant. The urban environment is characterized by the presence of an excessive number of obstacles that produce Multiple Path (MP) in positioning the receiver. Consequently, it is of primary importance to characterize and ameliorate the performances of GNSS receiver for this type of application. In this paper, a method to mitigate MP in GNSS applications was proposed. Its principle is based on the addition, to the geographic map of a city or a neighborhood, of a supplementary information that consists of the correction of error caused by the MPs. The latter one was carried out by the comparison of the measurements, realized by Differential GPS (DGPS) and GPS, between two different sites with the same form. The first one was characterized by the presence of the MPs and the second one was completely clear of any type of obstacle. As a consequence, the measurements comparison has allowed us to deduce the GNSS MPs errors. This information can subsequently be used to make the corrections of the errors caused by MPs and it can be generalized by a measurement company to any entire city in order to identify errors in any neighborhood.
\end{abstract}

\section{Keywords}

GNSS, GPS, DGPS, Multipath

\section{Introduction}

The first stage realized in a GNSS receiver consists of visible satellites acquisition, as well as a coarse estimate of signal in space (SIS) parameters corresponding to each satellite of the constellation [1]. This operation is accomplished by a 
block called acquisition circuit [2], which is a system based on the application of the estimation theory [3]. With the advent of the European system Galileo, certain modifications were made in the acquisition stage in order to optimally receive the new structures of SIS signals [4]. The main factor that has leaded the designers of the circuits to introduce these new acquisition strategies is the use of Binary Offset Carrier (BOC) modulation [5]. This recent new functionality was added to guarantee interworking between the new Galileo system and the modernized GPS by ensuring also a better performance in positioning the receiver [6]. In spite of all these advantages, this new type of modulation is not completely sheltered from the principal sources of the traditional problems confronted by old generation GPS [7], in particular MP and additive noise [8]. Moreover, BOC modulation represents another major disadvantage which is related to the existence of secondary peaks in its Correlation Function (CF) that can create ambiguity in the tracking process [9]. Several methods have been proposed for side peaks cancelation and true Delay Locked Loop (DLL) zerocrossing detection [10] [11] [12] [13] [14]. Nonetheless, the majority of them still have the problem of the existence of some secondary peaks or the invalidity in the presence of MPs [15] [16] [17] [18]. On the other hand, the application of these methods can lead to the loss of the positive effect of the BOC modulations on the improvement of the performances in the presence of the MP [19] [20]. This last represents a propagation phenomenon which results in the presence of radio signals at the input of the receiving antenna with quite a few copies [21]. The causes of these MPs include the reflection and the refraction of the bodies, water and the terrestrial objects such as the mountains, the buildings, and the trees [22]. As a consequence, the MP effect can hold a constructive or destructive intervention depending on the phases of the received signals [23] and as a result position miscalculations can reach values of some tens of meters for civil applications [24]. Several methods have been proposed in literature for MP mitigation in classical GPS receiver [25] [26]. The most basic of them are limited on BPSK modulated signals [27] [28]. The others are methods that have been evaluated by simulation results without being validated on real signals. Moreover, even in the case where the tests are performed with real signals, the majority of the methods use simulated MPs scene [29] [30] [31] [32] [33]. In this paper, we propose a method based on actual measurements, with GPS and DGPS, for MP error correction in an urban environment. The latter one is based on the comparison of GPS and DGPS measurements on real scenes. In fact, as an example we made a comparison between position measurements realized in two places $a$ and $\beta$ of the urban region called 12 Hectares in Bordj Bou Arreridj (Algeria). The place " $\alpha$ " is completely open (Clear of any type of obstacle) where we find all GNSS errors except of MP's ones. The place $(\beta)$ is characterized by the presence of more or less high buildings on both sides of the street where we find, in addition to MP error, all the other types of GNSS errors. Finally, these measurements and comparisons can be generalized by a measurement company to- 
ward an entire city to identify errors in any neighborhood. This paper is organized as follows: Section 2 describes the GPS signals in presence of MPs. In Section 3, we propose our scenarios for GPS and DGPS measurements and MPs error correction. Finally, the presentation of the results also some conclusions are summarized.

\section{GPS Signal in the Presence of MPs}

The most important characteristics of MP are as follows [27] [34] [35]:

$>$ Each MP component is generally associated with a longer path.

$>$ Each MP component shall have a lower power than the direct path.

$>$ We assume that there is only one reflected component. Moreover, we assume that the phase difference between the direct path and the reflected path is $0^{\circ}$ or $180^{\circ}$. This corresponds to the maximum error that a GNSS receiver can reach.

At the entrance of the receiver, the emitted signal by the satellite is composed of a direct signal and one or more reflected paths signals. Each one has a carrier that is modulated by a PN code and navigation data. After the passage a tan intermediate frequency, the signal is given as [2]:

$$
\begin{aligned}
S_{r}(t)= & \sum_{m=0}^{N} \sqrt{p} \cdot a_{m}(t) \cdot d\left(t-T_{m}(t)\right) \cdot p\left(t-T_{m}(t)\right) \\
& \cdot \sin \left\{W_{s}\left(t-T_{m}(t)\right)+\varnothing_{m}(t)\right\} \cdot \sin \left\{W_{i}\left(t-T_{m}(t)\right)+\varnothing_{m}\right\}
\end{aligned}
$$

With:

$W_{i}:$ Intermediate frequency.

$\varnothing_{m}$ : Total phase plus the Doppler shift.

$a_{m}(t)$ : Amplitude coefficient.

$d(t)$ : Navigation message emitted by the satellite.

$p(t)$ : Pseudo random code modulated with a subcarrier.

$T_{m}(t)$ : Total delay of propagation.

\section{Principle of the Proposed Method}

In this part, we will present the measurements that we made to perform the GPS MP correction. The latter ones have been realized through several records conceived with a view to identify and correct the different GPS problems in addition to that, the MP that can have an effect on the accurateness of positioning. The scenario is designed in order to study the effects of MPs inside an urban district. The aim here is to calculate via the GPS and the DGPS a number of spots spaced 15 meters from each other, in two places $\alpha$ and $\beta$, as shown in the satellite picture in Figure 1.

The place $(\alpha)$, represents the parking lot of the new train station. It is completely open except for a few small trees whose effect on the accuracy of positioning will be studied. The place $(\beta)$ is characterized by the presence of more or less high buildings on both sides of the street, with a rectangular shape similar to $(\alpha)$. In addition, the width of the street is not homogeneous, which offers a larger 


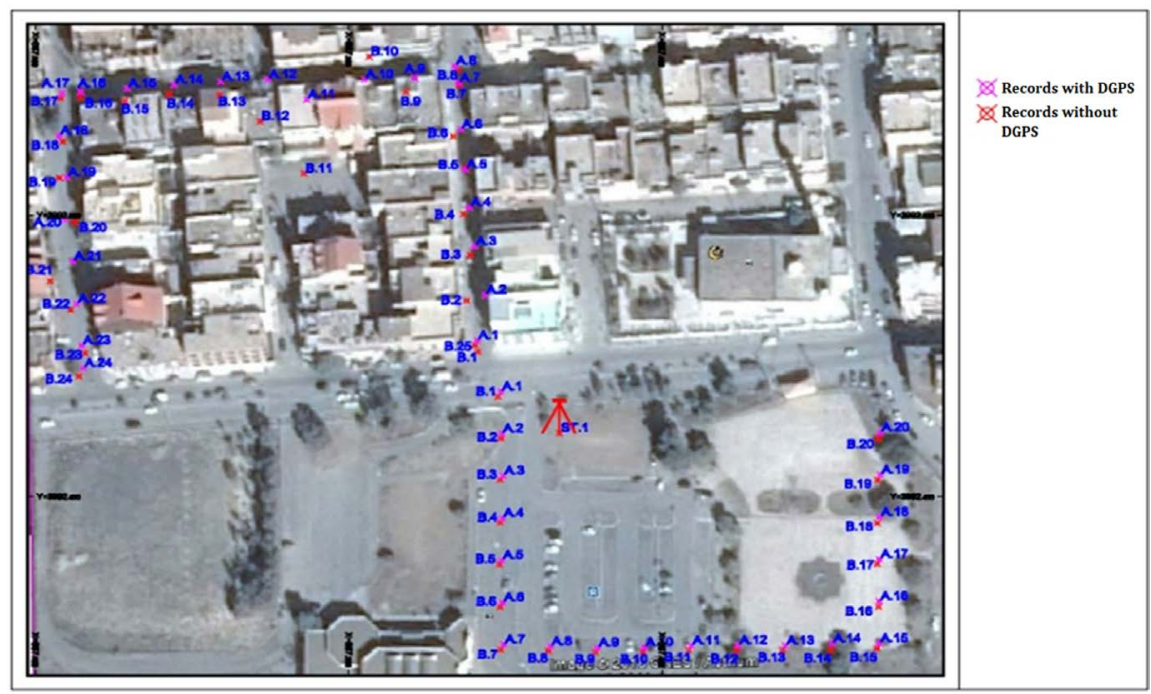

Figure 1. Overall vision of the places ( $\alpha$ and $\beta$ ).

observation window to the more spacious places, at the expense of the narrow ones. The place $(\alpha)$ is completely open where we find all GPS errors except MPs ones. In contrast, the place $(\beta)$ is a street characterized by the presence of high buildings where we find all GPS errors in addition to the MPs ones. Therefore, by the comparison of measurements results (with DGPS), we can distinguish the errors caused by MPs phenomena.

\section{Experimental Results}

As shown in Figure 2, all the illustrated points (in blue or in red) are obtained along a rectangular line in the $(\alpha)$ streets for the two following cases:

- Case 1: without DGPS correction Figure 2(a): the line is determined by the dots in red, going from B1 to B20.

- Case 2: with DGPS correction Figure 2(b): the line is determined by the dots in red, going from A1 to A20.

The result of calculating the dots in the $(\beta)$ streets is given in Figure 3. Here as well, we find the two cases:

- Case 1: without DGPS correction Figure 3(a): the line is determined by the dots in blue starting from B1 up to B24.

- Case 2: with DGPS correction Figure 3(b): the line is determined by the dots inred starting from A1 up to A24.

A number of important results can be derived from these records. According to the records in Figure 2 and Figure 3, we notice that:

- In the completely exposed area $(\alpha)$, the apparatus with DGPS correction gives the distances between the successive dots with a high accuracy (a centimeter gap). This confirms the efficiency of the apparatus in such places. However, the accuracy is reduced near the trees, such as in dots (B14, A14), (B18, A18), (B19, A19) and (B20, A20), and so the error rate increases.

This error is important when the mobile station is used alone, and it can reach 


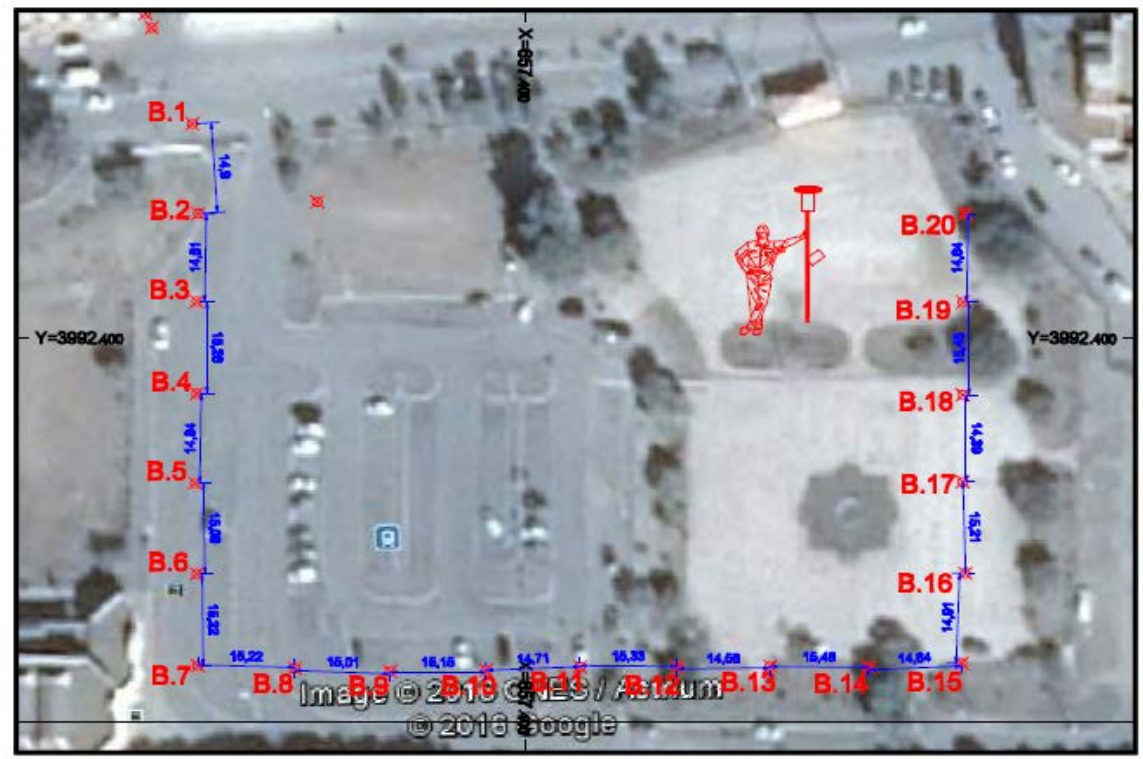

(a)

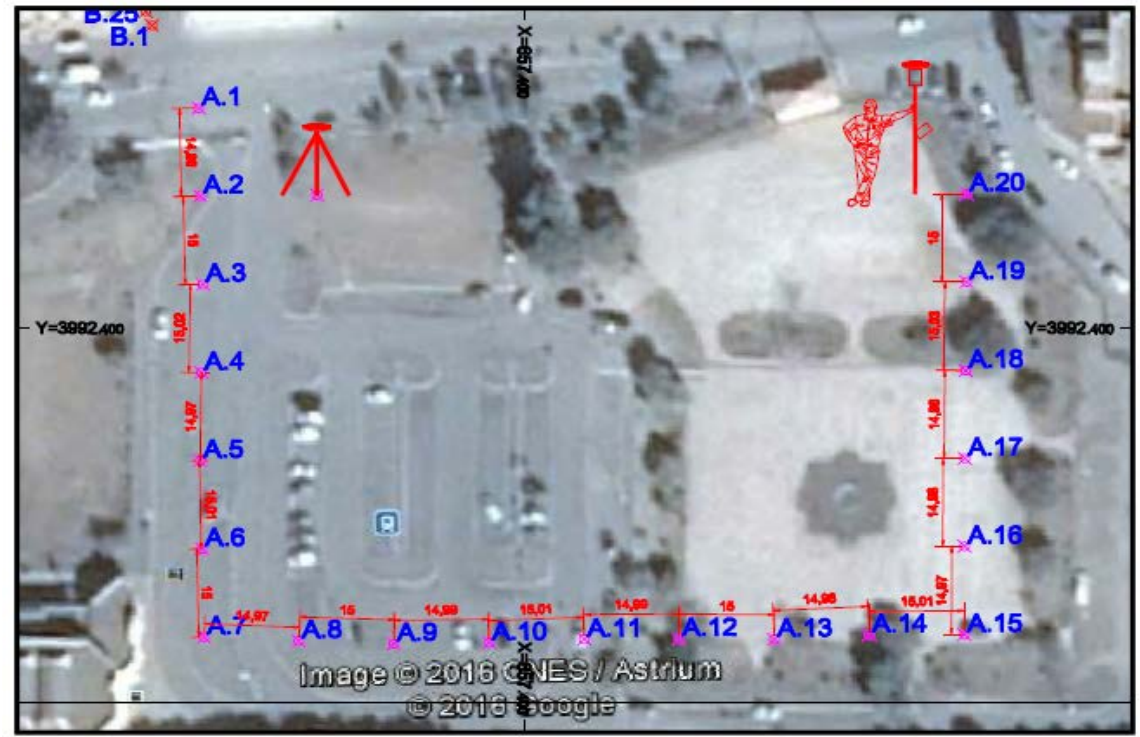

(b)

Figure 2. Topographical record of $(\alpha)$. (a) Points record in $(\alpha)$ without DGPS correction; (b) Points record in $(\alpha)$ with DGPS correction.

to $2 \mathrm{~m}$ in the typically bare place $(\alpha)$ (dots $(\mathrm{B} 7, \mathrm{~A} 7))$ and up to $28 \mathrm{~m}$ in place $(\beta)$ (points (B11, A11).

- Contrary to place $(\alpha)$, in the streets of the district ( $\beta$ ) (Figure 3), the accuracy is affected by several substantial factors such as:

$>$ The presence of trees: the bigger their volume, the less accuracy.

$>$ The sky vision window: the bigger it is; the better accuracy calculation gets. This last is conditioned by the height of the buildings as well as the width of the street. But where the buildings are less high and the street is wider, the sky vision window is greater and so the accuracy calculation of dots is better. 


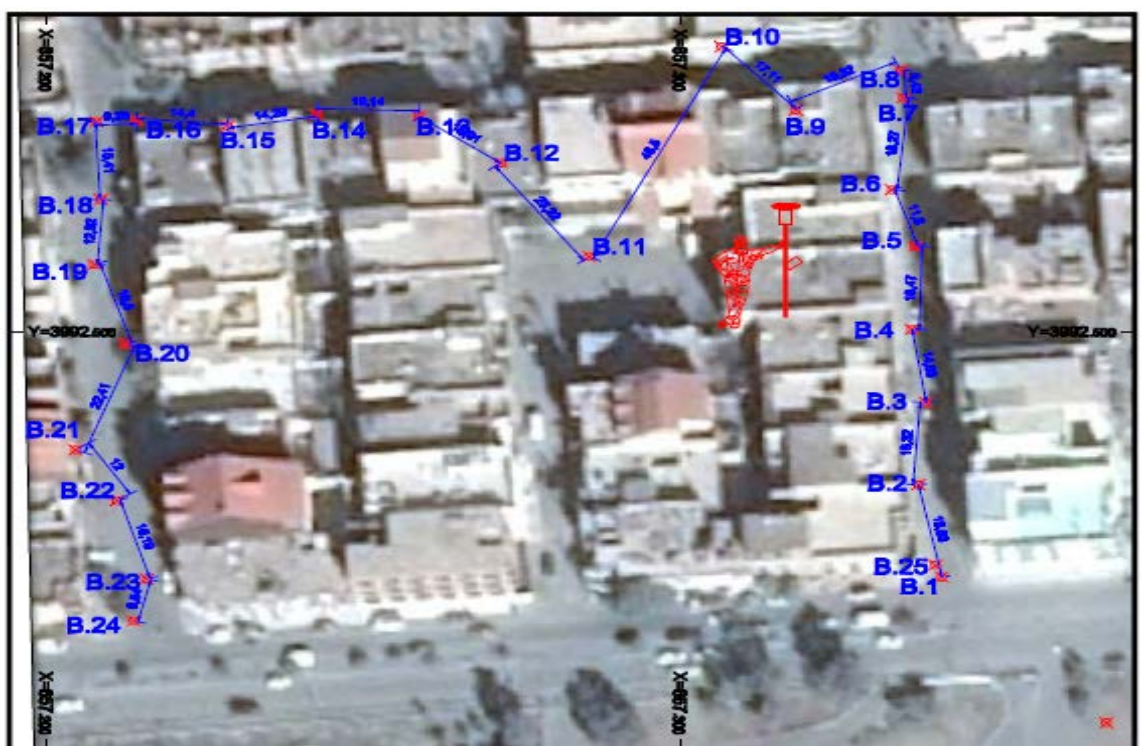

(a)

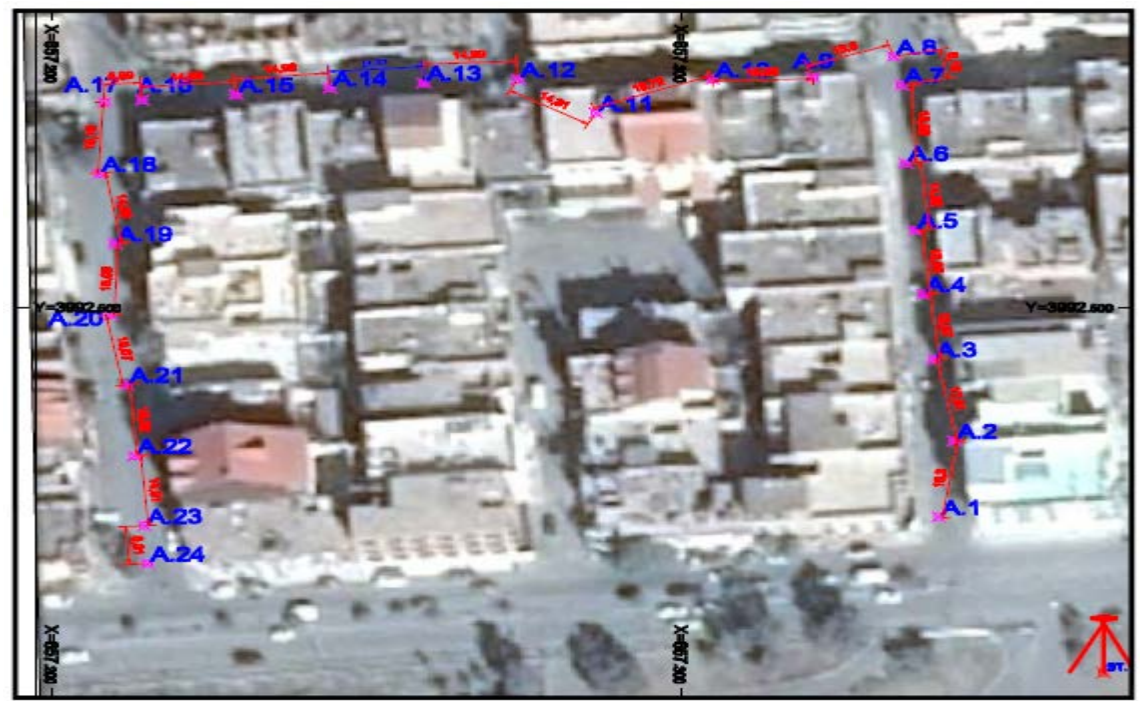

(b)

Figure 3. Topographical record of $(\beta)$. (a) Points record in $(\beta)$ without DGPS correction; (b) Points record in $(\beta)$ with DGPS correction.

D In contrary, we notice the reverse effect at crossroads, an improvement in accuracy calculation by the apparatus, mainly due in this case to the increase of the vision window.

$>$ The MP problem is caused by the walls of houses. In this scenario, we cannot properly speak of MP problem, though it does exist. The dominant reason in this case remains the extremely reduced vision window in the studied district, and which considerably prevents the satellite signals to reach the receiver.

\section{MP Error Correction}

In this part, we compare the records points in the area( $\beta)$ with and without the DGPS correction to illustrate the corrections to be applied to each measurement 
in order to minimize the effect of MP.

As illustrated in Figure 4, the comparison between all curves (depending on whether $\mathrm{x}$ or $\mathrm{y}$ ) can give the correction value corresponding to each point leading to the MP error reduction. With the same procedure, we can generalize the operation of MP correction for any point. All these values are resumed in Table 1.
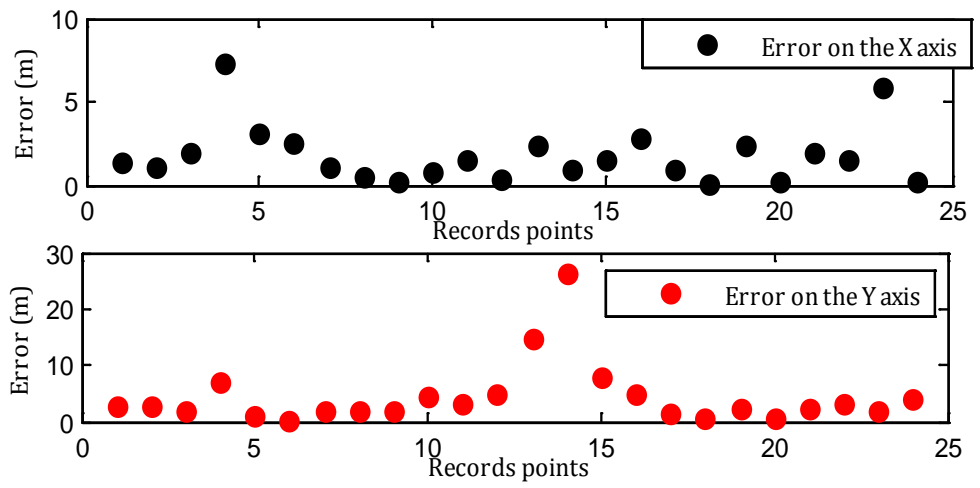

Figure 4. Comparison between GPS and DGPS.

Table 1. Comparison between GPS and DGPS.

\begin{tabular}{ccc}
\hline Records points & X axis & Y axis \\
\hline A1-B1 & 1.43 & 2.995 \\
A2-B2 & 1.105 & 2.694 \\
A3-B3 & 2.026 & 2.037 \\
A4-B4 & 7.337 & 7.011 \\
A5-B5 & 3.182 & 0.873 \\
A6-B6 & 2.485 & 0.208 \\
A7-B7 & 1.148 & 2.100 \\
A8-B8 & 0.451 & 1.833 \\
A9-B9 & 0.152 & 2.065 \\
A10-B10 & 0.733 & 4.374 \\
A11-B11 & 1.558 & 3.408 \\
A12-B12 & 0.353 & 4.852 \\
A13-B13 & 2.411 & 14.864 \\
A14-B14 & 0.882 & 26.315 \\
A15-B15 & 1.502 & 8.110 \\
A16-B16 & 2.781 & 4.850 \\
A17-B17 & 0.934 & 1.450 \\
A18-B18 & 0.094 & 0.819 \\
A19-B19 & 2.391 & 2.432 \\
A20-B20 & 0.147 & 0.567 \\
A21-B21 & 2.003 & 2.352 \\
A22-B22 & 1.52 & 3.060 \\
A23-B23 & 0.229 & 2.031 \\
A24-B24 & & 4.176 \\
\hline
\end{tabular}




\section{Conclusion}

In this paper, a method based on actual measurements, with GPS and DGPS, for MP error correction have been proposed. We have compared between measurements realized in two urban regions $\alpha$ and $\beta$, where in $\alpha$ there is no MP errors unlike $\beta$ which has MP errors. Before the realization of the considered various scenarios, we have constantly positioned points spaced of a pre-fixed distance, this points were also located according to a determined line. The found results, first of all, showed the incapacity of the mobile station without the DGPS correctors. Indeed, the accurateness of the results in this case decreased notably with several meters errors. On the other hand, the use of the two stations unit gave a centimetric precision. This precision was put to the test in two different circumstances. The first case is inside a district where we have the problems of the vision window and the trees. In this case, the results show a degradation in the accuracy of the GPS RTK which is accentuated with the reduction of the vision window and the presence of trees. The second considered situation is that of the space completely cleared in front of district where the first problem is absent. In this case, the results reveal clearly the effect of MPs which are caused primarily by the houses frontages of the bordering district. Therefore, by comparing the two results we distinguished the errors due to the MPs. Moreover, they show that this effect is trivial close to the houses and that it becomes increasingly significant when one moves away from there which is consistent with the nature and the physical aspect characterizing MPs.

\section{References}

[1] Sokhandan, N., Curran, J.T., Broumandan, A. and Lachapelle, G. (2015) An Advanced GNSS Code Multipath Detection and Estimation Algorithm. GPS Solutions, Springer, 1-14.

[2] Rouabah, K. and Chikouche, D. (2009) GPS/Galileo Multipath Detection and Mitigation Using Closed-Form Solutions. Mathematical Problems in Engineering, 1-20. https://doi.org/10.1155/2009/106870

[3] Cui, H., Li, Z. and Dou, Z. (2017) Fast Acquisition Method of GPS Signal Based on FFT Cyclic Correlation. International Journal of Communications, Network and System Sciences, 10, 246-254. https://doi.org/10.4236/ijcns.2017.108B026

[4] Rouabah, K., Chikouche, D., Bouttout, F., Harba, R. and Ravier, P. (2010) "GPS/ Galileo Multipath Mitigation Using the First Side Peak of Double Delta Correlator. Wireless Personal Communications, 321-333.

[5] Flissi, M., Rouabah, K., Chikouche, D., Mayouf, A. and Atia, S. (2013) Performance of New BOC-AW-Modulated Signals for GNSS System. EURASIP Journal on Wireless Communication and Networking, 1-18. https://doi.org/10.1186/1687-1499-2013-124

[6] Titouni, S., Rouabah, K., Flissi, M., Feneniche, W., Atia, S. and Chikouche, D. (2016) General Analytical Models Characterizing Multipath Running Average Error for C/A-GPS and BOC (n, n) Galileo Signals. Proceedings of 7 th International Conference: Sciences of Electronic, Technologies of Information and Telecommunications, Tunisia, 520-526. https://doi.org/10.1109/SETIT.2016.7939925 
[7] Zitouni, S., Rouabah, K., Atia S. and Chikouche, D. (2012) Comments on a General Model of Multipath Error for Coherently Tracked BOC Modulated Signals. Wireless Personal Communications-Springer, 1397-1407.

[8] Psiaki, M.L., Ertan, T., O’Hanlon, B.W. and Powell., S.P. (2015) GNSS Multipath Mitigation Using Antenna Motion. Journal of Institute of Navigation, 1-22. https://doi.org/10.1002/navi.79

[9] Lohan, E.S., Lakhzouri, A. and Renfors, M. (2006) Binary-Offset-Carrier Modulation Techniques with Applications in Satellite Navigation Systems. Wiley Journal of Wireless Communications and Mobile Computing, 767-779.

[10] Rouabah, K., Saifeddine, C., Atia, S., Flissi, M. and Chikouche, D. (2013) Mathematical Model of Non-Coherent-DLL Discriminator Output and Multipath Envelope Error for BOC $(\alpha, \beta)$ Modulated Signals. Positioning, 4, 65-79.

https://doi.org/10.4236/pos.2013.41008

[11] Woo, S., Chae, K., Liu, H. and Yoon, S. (2015) A Novel Cosine-Phased Binary Offset Carrier Signal Tracking. Proceedings of Int'l Conference, Wireless Networks, 98-101.

[12] Ren, J.W., Yang, G.T., Jia, W.M. and Yao, M.L. (2014) Unambiguous Tracking Method Based on CombinedCorrelation Functions for Sine/Cosine-BOC CBOC and AltBOC Modulated Signals. Radio Engineering, 23, 244-251.

[13] Shen, F., Xu, G., Cheong, G.W. and Feng, H. (2015) Unambiguous Acquisition and Tracking Technique for General BOC Signals. Radio Engineering, 24, 840-849. https://doi.org/10.13164/re.2015.0840

[14] Attia, S., Rouabah, K., Chikouche, D. and Flissi, M. (2014) Side Peak Cancellation Method for Sine-BOC(m,n)-Modulated GNSS Signals. Eurasip Journal on Wireless Communication and Networking. https://doi.org/10.1186/1687-1499-2014-34

[15] Liu, F. and Feng, Y. (2015) A New Acquisition Algorithm with Elimination Side Peak for All BOC Signals. Mathematical Problems in Engineering, 2015, Article ID: 140345. https://doi.org/10.1155/2015/140345

[16] Dempster, A.G. and Wu, J. (2008) Code Discriminator for Multiplexed Binary Offset Carrier Signals. IEEE Electronics Letters, 44, 384-385.

https://doi.org/10.1049/el:20080138

[17] Wu, J. and Dempster, A.G. (2011) Unambiguous Double Delta Correlator for Sine-Phased BOC(n,n) Receiver. Journal of Global Positioning System, 10, 149-156. https://doi.org/10.5081/jgps.10.2.149

[18] Yao, Z., Cui, X, Lu, M., Feng, Z. and Yang, J. (2010) Pseudo-CorrelationFunction-Based Unambiguous Tracking Technique for Sine-BOC Signals. IEEE Transactions on Aerospace and Electronic Systems, 46, 1782-1796. https://doi.org/10.1109/TAES.2010.5595594

[19] Dovis, F., Mulassano, P. and Lo Presti, L. (2005) A Novel Algorithm for the Code Tracking of $\operatorname{BOC}(\mathrm{n}, \mathrm{n})$ Modulated Signals. Proceedings of the 18 th International Technical Meeting of the Satellite Division of The Institute of Navigation, 152-155.

[20] Yao, Z., Lu, M. and Feng, Z. (2009) Unambiguous Technique for Multiplexed Binary Offset Carrier Modulated Signals Tracking. IEEE Signal Processing Letters, 16, 608-611. https://doi.org/10.1109/LSP.2009.2020462

[21] Sahmoudi, M. and Landry, R. (2008) Multipath Mitigation Techniques using Maximum-Likelihood Principle. Inside GNSS, 24-29.

[22] Rouabah, K., Flissi, M., Atia, S. and Chikouche, D. (2012) Unambiguous Multipath Mitigation Technique for BOC (n,n) and MBOC-Modulated GNSS Signals. Interna- 
tional Journal of Antennas and Propagation, 2012, Article ID: 895390. https://doi.org/10.1155/2012/895390

[23] Nee, V. (1994) The Multipath Estimating Delay Locked Loop Approaching Theatrical Accuracy Limits. IEEE Position, Location and Navigation Symposium, Las Vegas, 11-15 April 1994, 246-251.

[24] Borio, D. and Presti, L.L. (2008) Data and Pilot Combining for Composite GNSS Signal Acquisition. International Journal of Navigation and Observation, 2008, Article ID: 738183. https://doi.org/10.1155/2008/738183

[25] Van Dierendonck, A.J., Fenton, P. and Ford, T. (1992) Theory and Performance of Narrow Correlator Spacing in a GPS Receiver. Navigation: Journal of the Institute of Navigation, 39, 265-283. https://doi.org/10.1002/j.2161-4296.1992.tb02276.x

[26] Townsend, B. and Fenton, P. (1994) A Practical Approach to the Reduction of Pseudo Range Multipath Errors in a L1 GPS Receiver. Proceedings of ION GPS USA, 143-148.

[27] Braasch, M.S. and Van Dierendonck, A.J. (1999) GPS Receiver Architectures and Measurements. Proceedings of the IEEE, 87, 48-64.

https://doi.org/10.1109/5.736341

[28] Mcgraw, G.A. and Braasch, M.S. (1999) GNSS Multipath Mitigation using Gated and High Resolution Correlator Concepts. Proceedings of the National Technical Meeting of the Satellite Division of the Institute of Navigation San Diego.

[29] Chen, X. and Morton, Y. (2015) Iterative Subspace Alternating Projection Method for GNSS Multipath DOA Estimation. IET Radar, Sonar \& Navigation, 1-10. https://doi.org/10.1049/iet-rsn.2014.0037

[30] Irsigller, M. and Eissfeller, B. (2003) Comparison of Multipath Mitigation Techniques with Consideration of Future Signal Structures. Proceedings of ION GNSS USA, 2584-2592.

[31] Jones, J., Fenton, P. and Smith, B. (2004) Theory and Performance of the Pulse Aperture Correlator. Tech Report NovAtel Canada, 1-13.

[32] Phelts, R.E. and Enge, P. (2000) The Multipath Invariance Approach for Code Multipath Mitigation. Proceedings of ION GPS UT USA, 2376-2384.

[33] Hurskainen, H., Lohan, E. S., Hu, X., Raasakka, J. and Nurmi, J. (2008) Multiple Gate Delay Tracking Structures for GNSS Signals and Their Evaluation with Simulink, System C, and VHDL. International Journal of Navigation and Observation, 1-17. https://doi.org/10.1155/2008/785695

[34] Kalyanaraman, S.K., Kelly, J.M., Braasch, M.S. and Kacirek, J. (2004) Influence of GPS Code Tracking on Multipath Performance. Aerospace Conference, Proceedings, Vol. 3, 1677-1686. https://doi.org/10.1109/AERO.2004.1367943

[35] Kovář, P., Vejražka, F., Seidl, L. and Kačmařík, P. (2005) Galileo Receiver Core Technologies. Journal of Global Positioning Systems, 4, 176-183.

https://doi.org/10.5081/jgps.4.1.176 